\title{
LAS MEDIDAS Y LA APLICACIÓN DEL ARTÍCULO 155 CE A CATALUÑA
}

\section{The measures and how should be applied the content of 155 constitutional section in Catalonia}

\author{
GERMÁN GÓMEZ ORFANEL \\ Universidad Complutense de Madrid \\ germango@ucm.es
}

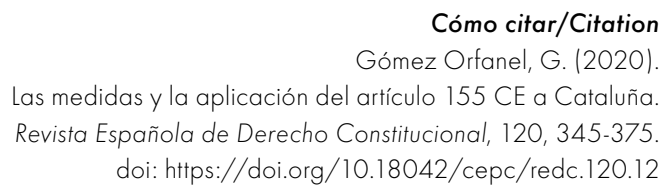

\section{Resumen}

El artículo analiza la naturaleza y los diferentes tipos de medidas en relación con la coerción federal o estatal, destacando la singularidad de justificar la intervención del Estado cuando se produzca no solo un incumplimiento de obligaciones jurídicas sino un atentado al interés general de Espańa, lo que introduce una perspectiva política. Se centra más adelante en las medidas utilizadas en la única ocasión en que se ha aplicado el art. 155 CE (octubre de 2017) y en la ejecución de estas respecto al cese del Gobierno y la disolución del Parlamento de Cataluña, reflejando, además, el debate generado entre sus partidarios y opositores acerca de su eficacia y constitucionalidad ratificada casi en su totalidad por las dos sentencias del Tribunal Constitucional de julio de 2019.

\section{Palabras clave}

Coerción federal o estatal; interés general de España; cese del Gobierno; disolución del Parlamento; medidas; Cataluña; conflictos territoriales; Tribunal Constitucional español. 


\begin{abstract}
This paper analyses, which is the nature of the federal and state coercion and what would be the accurate tools to evolve such coercion. But must highlight the great relevance of the State, acting against breaching of legal duties and even more, when such defaults mean a profound risk for the Spanish general interest. Besides, that could mean a new political view. After that, the paper is focussing on the exclusive occasion in which was applied the content of the 155 section over Catalonia (October 2017) and in the manner, in which those measures were developed provoking the dissolution of the Catalonian parliament and the dismission of its executive branch. In the same way, it was generated a deep debate between supporters and detractors around the significance of 155 . What is really its effectiveness, after having been declared almost fully according to the constitution by the Spanish Constitutional Court through the two known judgment in July in 2019.
\end{abstract}

\title{
Keywords
}

Federal and state coercion; Spanish general interest; dismission of Government; dissolution of Parliament; measures; Catalonia; territorial conflicts; Spanish Constitutional Court. 
I. LA NOCIÓN DE MEDIDA Y SU TIPOLOGÍA. II. LA SINGULARIDAD DEL ATENTADO AL INTERÉS GENERAL DE ESPAÑA. III. LAS MEDIDAS CONTENIDAS EN LA PROPUESTA DEL GOBIERNO APROBADA POR EL SENADO. IV. LA EJECUCIÓN DE LAS MEDIDAS. V. EL GRAN DEBATE: LA LEGITIMIDAD CONSTITUCIONAL DEL CESE DEL GOBIERNO Y DE LA DISOLUCIÓN DEL PARLAMENTO. VI. ALGUNAS REFERENCIAS SOBRE LA APLICACIÓN DE LAS MEDIDAS: 1. La posición del Gobierno en las comparecencias ante la Comisión Conjunta del Senado. 2. La perspectiva soberanista. VII. LA DECISIÓN DEL TRIBUNAL CONSTITUCIONAL SOBRE LAS MEDIDAS APROBADAS Y SU EJECUCIÓN. BIBLIOGRAFÍA.

\section{LA NOCIÓN DE MEDIDA Y SU TIPOLOGÍA}

Determinar a priori el catálogo de medidas que emplear supone una tarea problemática, máxime al limitarse el texto constitucional a establecer una cláusula general finalista, las medidas necesarias para lograr el cumplimiento de las obligaciones o la protección del interés general, de manera que la obtención del resultado propuesto legitime la acción.

La coerción federal o estatal es, pues, un poder basado en medidas. Schmitt las definía como "acciones individualizadas o disposiciones generales adoptadas a la vista de una situación concreta que se considera anormal y superable, pero que no pretenden una vigencia por tiempo indefinido» (1924: 104). Lo característico de la medida radicaría en su dependencia finalista de la situación objetiva concreta, con la consecuencia de que su magnitud, procedimiento y eficacia se determinarían en cada caso por la naturaleza de las circunstancias.

Las medidas constituyen también el contenido típico de los poderes de excepción. A título de muestra recordemos el célebre art. 16 de la Constitución francesa de $1958^{1}$, vigente en la actualidad y que sirvió de inspiración a nuestra Ley Orgánica del Estado de $1967^{2}$. En cualquier caso, el ejemplo

1 «Cuando las instituciones de la República, la independencia de la Nación, la integridad de su territorio o la ejecución de sus compromisos internacionales resultaren amenazados de modo grave e inmediato y el funcionamiento regular de los poderes públicos constitucionales quedase interrumpido, el Presidente de la República adoptará las medidas exigidas por tales circunstancias [...]».

2 Art. 10: «El Jefe del Estado estará asistido por el Consejo del Reino para [...] d) Adoptar medidas excepcionales cuando la seguridad exterior, la independencia de la 
paradigmático sigue siendo el art. 48 de la Constitución de Weimar, que incluía en su primer apartado la ejecución federal (Reichsexecution), y en el segundo, el poder dictatorial (Diktaturgewalt) o de excepción con el resultado de equiparar instituciones diferentes, aunque coincidentes con bastante frecuencia.

Sin embargo los Estados contemporáneos, sean Estados de derecho sociales o no, acostumbran a emplear constantemente medidas como instrumento de intervención en el sistema económico y social utilizando también las denominadas leyes-medida (Gómez Orfanel, 1986: 238-248 y 217-226), muy frecuentes en situaciones de crisis económicas y sociales. Cuando escribo estas páginas (mayo de 2020) bajo el estado de alarma del art. 116.1 CE, debido a la pandemia de la covid-19, comprendo mejor el uso de las medidas en relación con la enorme crisis sanitaria global.

La adopción de medidas coercitivas se halla sometida en nuestro sistema a límites constitucionales. El fundamento de la intervención del Estado debe ser el de garantizar el cumplimiento de la Constitución y de las leyes, así como proteger el interés nacional, aunque esto último pueda ser un elemento distorsionante dentro del art. 155. Por ello debe impedirse que las medidas que se adopten sean utilizadas con vocación de alterar las estructuras constitucionales. Sería un contrasentido que para defender la Constitución por un lado fuese objeto de ataque por otro. La polémica surgida en torno a si la adopción de medidas extraordinarias puede servir de justificación para suspender o transformar de modo sustancial la Constitución debe zanjarse con una respuesta negativa. No suponen un cheque en blanco en manos del Gobierno, aun autorizado por el Senado.

$\mathrm{El}$ art. 155 alude a medidas necesarias, y tal requisito hay que interpretarlo conforme a diversos principios jurídicos:

a) En primer lugar, el principio de proporcionalidad, o también de prohibición de exceso, en cuanto que norma aplicable en todos los ámbitos de la actividad estatal y cuyo rango constitucional deriva del principio constitucional del Estado de derecho.

El Tribunal Constitucional Federal alemán se ha referido en múltiples sentencias al contenido de dicho principio, en el sentido de que la intervención debe ser idónea para la protección eficaz del bien jurídico, y debe ser, además, necesaria, lo cual no sucederá cuando existan alternativas de actuación menos intensas y que permitan lograr el objetivo

Nación, la integridad de su territorio o el sistema institucional del Reino estén amenazados de modo grave e inmediato, dando cuenta documentada a las Cortes». 
propuesto. En relación con este punto se situaría el principio de menor intervención en los derechos afectados. Finalmente, la intervención debe ser proporcionada en sentido estricto, el medio debe encontrarse en una relación adecuada (justa o razonable) con el fin al que se aspira (Kluth, 1998: 219 y ss.). Como ejemplos jurisprudenciales, BVerfGE 38, 281 (302), 67,157 (173), y 80,137 (159 y ss.), entre otros.

b) Principio de provisionalidad. Una vez restaurado el orden, se debe volver a la situación normal, al ejercicio de las competencias conforme a lo dispuesto en la Constitución. Provisionalidad o transitoriedad no suponen imponer necesariamente un plazo a la intervención.

c) Principio de concreción. El Reglamento del Senado exige precisar el contenido y alcance de las medidas propuestas (art. 189.1), a lo que se condiciona la aprobación de la Cámara favoreciendo el eventual control posterior por parte del Tribunal Constitucional (Calafell Ferrá, 2000: 127-129).

F. Moderne y P. Bon (1981: 155), en un trabajo publicado pocos ańos después de la aprobación de la Constitución de 1978, aludieron a que el contenido del art. 155 permitía una amplia variedad de medidas dirigidas a obligar a la correspondiente comunidad autónoma a que respetara la Constitución, la ley o el interés general afectados. Por ello, se otorgaban al Gobierno facultades de suspensión, anulación, reforma o sustitución sobre actos de la comunidad autónoma, dejando abierta la posibilidad de ejercer un control sobre los propios órganos autonómicos y llegando si fuese preciso a la disolución, quizá la expresión no es la adecuada, de lo que ellos denominaron órgano colegiado superior, para referirse al Gobierno.

Entre las medidas que cabe adoptar en un procedimiento de coerción o compulsión estatal, citaremos, en primer lugar, las de sustitución, caracterizadas por la actuación del Estado central en lugar de los órganos autonómicos que no han cumplido sus obligaciones, o no han respetado el tantas veces citado interés general. Estaríamos ante una ejecución sustitutiva, subsidiaria o forzosa. El Estado puede actuar directamente a través de sus órganos centrales o periféricos o mediante órganos de la comunidad o suspendiendo actos autonómicos.

A estos efectos se comprende el párrafo 2 del art. 155, la facultad de impartir instrucciones a las autoridades de las comunidades autónomas, como algo diferente a las medidas, es decir, que se las sitúa en una posición de subordinación jerárquica, que es lo opuesto a la autonomía. La sustitución afecta, generalmente, a los órganos ejecutivos, planteándose mayores dificultades cuando pretende extenderse a los órganos legislativos representantes del pueblo, de los ciudadanos de la comunidad autónoma. 
En relación con la aplicación del derecho comunitario europeo, y teniendo en cuenta las experiencias italianas, nuestro Consejo de Estado recomendó introducir en el derecho español un mecanismo semejante de intervención preventiva y sustitutiva, «en aquellos casos en que el desplazamiento de la competencia normativa autonómica por la estatal se presente como la única forma de que España cumpla sus obligaciones frente a la Unión Europea» (Informe del Consejo de Estado sobre la inserción del Derecho europeo en el ordenamiento español, 2008: 173-174).

En Italia, la reforma constitucional de octubre de 2001 reguló de forma injustificadamente amplia los poderes de sustitución del Gobierno respecto a las regiones cuando estas no respeten normas o tratados internacionales o comunitarios de la Unión Europea, por razones de seguridad pública, y para tutelar la unidad jurídica y económica.

Las opiniones están divididas en lo tocante a la disolución de órganos autonómicos. Podemos distinguir aquí entre varios supuestos:

- Disolución o suspensión de la comunidad autónoma. Considero que es una medida inaceptable por anticonstitucional, al dejar en manos del poder central la disposición sobre la autonomía, y que en el fondo supone una sanción a los ciudadanos de esa comunidad autónoma. Los alemanes utilizan una expresión rotunda para este caso, Liquidation. La función de la coerción no es represiva, sino compulsiva, y no pueden dirigirse directa o inmediatamente contra el pueblo del Land. Por otro lado, la existencia de los Länder forma parte del núcleo irreformable de la ley fundamental (art. 79.3, en conexión con el 28).

Un ejemplo de ello lo tenemos en nuestra historia con la suspensión del Estatuto de Cataluña por la Ley de 2 de enero de 1935, que fue declarada contraria a la Constitución, ya que «la suspensión del régimen autonómico establecido en la Ley podría convertirse en medio de derogar prácticamente el Estatuto» (Sentencia del TGC de 5 de marzo de 1936).

- Disolución o suspensión de órganos autonómicos. Cuando la sustitución no sea de carácter puntual e inmediato, sino que exija una sustitución generalizada aunque transitoria de los órganos de la comunidad, estaremos ante una suspensión o Sequestration, y gran parte de la doctrina alemana la admite en relación con la coerción, siempre que no se extienda a la disolución del Parlamento.

Profesores italianos ya clásicos, como Vandelli (1982: 331), o de influencia italiana (Tolivar Alas, 1981: 187) han aceptado con facilidad la disolución de órganos legislativos autonómicos y la destitución de los 
ejecutivos. El art. 126 de la Constitución italiana contempla la disolución del Parlamento regional (Consiglio regionale) y la destitución del presidente de un Gobierno regional en los supuestos de vulneración de la Constitución o de las leyes, o incluso por razones de seguridad nacional, aparte de otros motivos, lo que limita profundamente la garantía de la autonomía regional. La Constitución austriaca mantiene la posibilidad de disolver un Parlamento estatal con la aprobación del Consejo Federal (art. 100).

Otros autores como Aja (1985: 474) y Gil-Robles (1988: 514) opinaron hace ya bastantes años que no puede llegarse a la disolución o suspensión de órganos autonómicos. Respecto al nombramiento de delegados especiales o comisarios del Gobierno central con poderes generales o especiales, la tradición alemana es abundante en ejemplos, y es una fórmula aceptable que entre nosotros ha defendido García Torres (1984: 1286).

La ley italiana de 5 de junio de 2003 (legge La Loggia) contemplaba, dentro de los poderes de sustitución, la posibilidad del nombramiento de comisarios ${ }^{3}$.

- Empleo de las Fuerzas Armadas. En principio, se puede afirmar que su utilización como instrumento represivo y máxima expresión de la weberiana coacción legítima del Estado supondría una medida excluida a no ser que se declare el estado de sitio, procedimiento previsto en otro lugar de la Constitución (art. 116).

Es cierto que corresponde a las Fuerzas Armadas defender el ordenamiento constitucional, y la integridad territorial de Espańa y que la conducta de alguna comunidad autónoma puede ponerlas en peligro, pero la eventual intervención militar tendría que llevarse a cabo por los cauces previstos en la propia Constitución y en las leyes correspondientes y bajo la dirección del Gobierno. Cuestión distinta es el empleo de elementos militares en el ámbito de la protección civil para combatir catástrofes naturales o sanitarias, como sería la intervención de la Unidad Militar de Emergencias (UME). Por otro lado, algunos contenidos de la peculiar Ley 36/2015, de Seguridad Nacional, que hasta el momento no se ha aplicado, podrían dar cobertura a intervenciones de fuerzas militares (Álvarez García, 2019). En tal perspectiva no faltan opiniones favorables (García Torres, 2019a: 155) a la compatibilidad entre medidas coercitivas del art. 155 y la declaración

«[...] il Consiglio dei ministri [...] adotta i provvedimenti necessari, anche normativi, ovvero nomina un apposito commissario» (art. 8, párrafo 1). 
de interés para la seguridad nacional (arts. 24 y ss.), en contraste con otras que destacan la ausencia de relación entre la Ley de Seguridad Nacional y el art. $155 \mathrm{CE}$, que no es la vía para habilitar la intervención de las fuerzas armadas (Nieto Jiménez, 2020: 235).

Dicho esto, la utilización de fuerzas militares en el interior debería reconducirse al estado de sitio para combatir, en caso de que no bastaran otros medios, insurrecciones o actos de fuerza contra la soberanía o independencia de España, y su integridad territorial, y, sobre todo, contra el ordenamiento constitucional (art. 32.1 de la Ley Orgánica 4/1981), que englobaría los supuestos anteriores. Desde una perspectiva de derecho comparado (Gómez Orfanel, 2005: 46 y ss.), tales actuaciones militares estarían conectadas más con situaciones de intervención federal o los estados de excepción (Alemania: arts. 35, $87 \mathrm{a} .2$, y 80 a, 91 y 115 y ss. LF) que con la coerción federal en un sentido estricto (art. 37 LF). Respecto al empleo de las fuerzas y cuerpos de seguridad estatales en aquellas comunidades que tuvieran atribuidas competencias de orden público, habrá que tener en cuenta lo dispuesto en los correspondientes estatutos (arts. 164 del Est. Cat. y 17.6 del Est. Vasco).

- Medidas de presión económicas o financieras. Se consideran admisibles con condiciones (proporcionalidad, no dirigidas contra la población...). Podemos pensar en actuaciones tales como la suspensión de asignaciones presupuestarias a las CC. AA. incumplidoras, de participaciones en los ingresos del Estado y transferencias del Fondo de Compensación Interterritorial. Medidas como la suspensión de la cesión de tributos, y, sobre todo, de los Conciertos Económicos, aparte de ser discutibles, tendrían, sin duda, un extraordinario impacto político. La Ley Orgánica 2/2012, de 27 de abril, de Estabilidad Presupuestaria y Sostenibilidad Financiera, aprobada como desarrollo de la reforma constitucional del art. $135 \mathrm{CE}$, imponía a las comunidades autónomas una serie de obligaciones cuyo incumplimiento generaba finalmente la aplicación del 155 (art. 26.1). Recurrido tal supuesto ante el Tribunal Constitucional, la STC 215/2014 confirmó la constitucionalidad de la regulación, aunque con el voto disidente de cinco magistrados.

García Torres, uno de los más relevantes estudiosos del art. 155, nos ha ofrecido, analizando la doctrina alemana interpretadora de la Bundeszwang del art. 37 LF, un catálogo de posibles medidas admisibles en contraste con otras inadmisibles para el ejercicio de la coerción federal o estatal. Entre las 
primeras se situarían, entre otras: las medidas de presión económicas y financieras y la negativa provisional a cumplir deberes federales respecto al Land, la ejecución sustitutoria, el nombramiento de comisarios y el ejercicio transitorio de poderes del Land mediante órganos federales...

Mientras que se considerarían rechazables: el empleo del ejército federal, aunque la utilización de fuerzas policiales se presentaría doctrinalmente como discutible, y la intervención en el Poder Judicial del Land, y, con mayor motivo, serán improcedentes la disolución o liquidación de este y la imposición de una nueva constitución, así como, y esto nos afectaría notablemente, la disolución del Parlamento o el cese del Gobierno del Land (García Torres, 2019a: 140-141).

\section{LA SINGULARIDAD DEL ATENTADO AL INTERÉS GENERAL DE ESPAÑA}

Dentro del contenido del art. $155 \mathrm{CE}$ nos encontramos con el elemento en el que la frontera entre lo jurídico y lo político se halla más diluida, o, con otras palabras, ante una manifiesta irrupción de la política dentro del texto constitucional. Entiendo que, a diferencia de la constatación de un incumplimiento de obligaciones jurídicas, el pronunciarse sobre la determinación del interés general de España, o sobre su grave vulneración, supone una decisión sustancialmente política, otra cosa es su posible vinculación con parámetros jurídicos.

El interés de los Estados ha sido históricamente una categoría clave para la elaboración de las doctrinas sobre la razón de Estado según uno de sus más conocidos estudiosos: «La finalidad del interés es siempre el crecimiento o, al menos, el mantenimiento del Estado. Por ello, tiene que cambiar con el tiempo" (Meinecke, 1983: 170).

En 1635 Henri de Rohan publicó en París su célebre discurso sobre el interés de los príncipes y Estados, cuyas primeras líneas no me resisto a transcribir:

Los príncipes dirigen a los pueblos y el interés a los príncipes. El conocimiento de este interés está tan por encima de las acciones de los príncipes, como ellos mismos lo están por encima de los pueblos. El príncipe se puede equivocar, su consejo puede estar corrompido, pero el interés es el único que no puede faltar jamás. Según que sea bien o mal comprendido, hace vivir o morir los Estados [...]. Para ello es preciso establecer como base que hay dos potencias en la Cristiandad que son como los dos polos de los que provienen los influjos de paz y 
guerra sobre los demás Estados, a saber, las Casas de Francia y de España. La de España se vio engrandecida de repente y no ha podido ocultar el deseo que tiene de convertirse en dueña y alzar en occidente el sol de una nueva monarquía (1988: 73-74).

Me he detenido especialmente en el comentario de esta visión del interés de España en la época del absolutismo para subrayar que en la actualidad todas las categorías incluidas en el texto constitucional deben interpretarse desde la lógica constitucional, es decir, conforme a la Constitución entendida como unidad y sistema y no contra la Constitución o alguno de sus principios básicos. No participo de la opinión de Cruz Villalón, quien considera que nos encontraríamos ante una cláusula de plenos poderes que podría dar lugar a la dictadura constitucional (1981: 713), pero sí creo que, a diferencia del primer supuesto, el incumplimiento de obligaciones constitucionales o legales, la alusión al interés general de España nos sitúa al menos en un escenario de control de la comunidad autónoma por parte del Estado relacionado con razones de oportunidad.

La Constitución incluye en diversos preceptos referencias a los conceptos de interés, interés público, interés nacional e interés general, además del interés general de España del art. 155 (González Hernández, 2013: 1523 y ss.). Bien como criterio para la distribución de competencias a favor del Estado (art. 149.1.20. ${ }^{\mathrm{a}}$ y 24. ${ }^{\mathrm{a}}$, "puertos y obras públicas de interés general»), o de las comunidades autónomas («interés de la Comunidad Autónoma», en el art. 148.1.4. $.^{\mathrm{a}} 10 \mathrm{a}^{\mathrm{a}}, 15 \mathrm{a}^{\mathrm{a}}$, y 16.a , pero también para delimitar el ámbito de autonomía de municipios, provincias y comunidades autónomas (art. 137, "gestión de sus respectivos intereses»). Desde otra perspectiva, como señaló Vandelli (1982: 281), para justificar intervenciones excepcionales del Estado, como leyes de armonización, «cuando así lo exija el interés general» (art. 150.3), o los supuestos del art. 144, "por motivos de interés nacional». En otros lugares de la Constitución se afirma que la «Administración Pública sirve con objetividad los intereses generales» (art. 103), o se proclama con gran solemnidad falta de realismo y sin tener en cuenta las posteriores vinculaciones supranacionales a la Unión Europea que «[t]oda la riqueza del país en sus distintas formas y sea cual fuere su titularidad está subordinada al interés general» (art. 128.1). No obstante, este artículo ya es en la actualidad objeto de significativos debates ante la expectativa de que pueda ofrecer cobertura a determinadas políticas de respuesta a la crisis económica y social generada por la pandemia.

Sin embargo, y volviendo al análisis de nuestro art. 155, ¿por qué este segundo supuesto del atentado grave al interés general de Espańa, que parece 
reflejar una dicotomía entre el jurídico incumplimiento de obligaciones constitucionales y legales y el bastante más político atentado grave al interés general de España?

¿Cuáles fueron las razones para apartarnos radicalmente del modelo que imitar, el art. 37 de la ley fundamental alemana, regulador de la coerción federal?

Esta sería, en opinión de García Torres, «la aparentemente más grave dificultad hermenéutica que el artículo 155 plantea" (1984: 1266). Por ello, una gran parte de la doctrina española ha procurado dar respuesta a la cuestión siguiente: ¿puede ser objeto de coerción estatal una comunidad autónoma que, cumpliendo sus obligaciones constitucionales y legales, considere el Gobierno de la nación, con la ratificación del Senado, que, aun así, ha atentado gravemente contra el interés general de España?

En principio, de la lectura del art. 155 se desprende que se trata de dos supuestos distintos separados gramaticalmente por la conjunción disyuntiva $o$, bastando la existencia constatada de cualquiera de ellos para poder poner en marcha el procedimiento de coerción. Ante esta afirmación se han producido diversas opiniones, entre las que citaría las siguientes.

a) En primer lugar, la de quienes equiparan ambos supuestos argumentando que no es posible una actuación que atente gravemente contra el interés general de España, sin atentar directamente a la Constitución (Muñoz Machado, 1982: 457) y sin incumplir al mismo tiempo alguna obligación constitucional o legal, y a la inversa, una comunidad autónoma que cumpla tales obligaciones no podrá atentar gravemente contra el mencionado interés, sería, me atrevo a afirmar, ontológicamente imposible.

A ello se añadiría la consideración del interés general de España como un típico concepto jurídico indeterminado, constitucionalizado en la medida en que tiene que ser determinado e interpretado conforme a parámetros jurídicos como son los principios constitucionales de unidad, autonomía, igualdad, solidaridad y proporcionalidad.

b) El otro modelo de respuestas se ha basado en buscar para nuestro sistema constitucional el equivalente al deber de fidelidad (Treue$p f l i c h t)$ o, sobre todo, al de lealtad federal (Bundestreue) alemanes, en cuanto que principios constitucionales no escritos, implícitos en la LF y reconocidos por la jurisprudencia del Tribunal Constitucional Federal y también por nuestro Tribunal Constitucional.

En esta línea, la conducta de una comunidad autónoma que atentare gravemente contra el interés general de España supondría per se un incumplimiento de lo que podría traducirse como obligación 
constitucional de fidelidad. El art. 155 sería «una plasmación del principio de lealtad al Estado autonómico» (Álvarez Álvarez, 2016: 279).

Ahora bien, la Bundestreue es una obligación recíproca entre la Federación y los Estados miembros y entre estos entre sí para comportarse con lealtad y prestarse comprensión y apoyo. En nuestro modelo constitucional, dado que las comunidades autónomas, y no solo el Estado central, también son España, un ejercicio injustificado o abusivo de la coerción estatal supondría, asimismo, una infracción de deberes constitucionales y un grave atentado al interés general de Espańa, con la consecuencia de que, al ser la coerción un mecanismo unidireccional y expresión de la hegemonía del Estado, a la comunidad o comunidades autónomas afectadas les quedaría el consuelo de acudir a la jurisdicción constitucional. En síntesis, se argumenta que ambos supuestos no serían alternativos sino equivalentes, o que el atentado al interés de España no es algo adicional al incumplimiento de obligaciones, sino un caso particularmente grave y, por ello, expresamente destacado de incumplimiento (García Torres, 1984: 1268). Bastantes años más tarde García Torres ha escrito que medidas tan decisivas como la destitución del presidente y la disolución del Parlamento catalán «pudieran justificarse como medidas protectoras del interés general de España si a éste segundo supuesto se le da una interpretación que permita un amplísimo margen de apreciación política, de manera que [...] fuera menos justiciable que el de incumplimiento» (2019a: 142; 2019b: 515-518). No han faltado opiniones en el sentido de afirmar que el atentado contra el interés general de España "sería un incumplimiento y de los más graves de la indefectible obligación constitucional de garantizar la unidad e integridad de su soberanía política y territorial» (González Hernández, 2016: 539).

Si los supuestos son equiparables, ¿por qué incluir el segundo en el enunciado del artículo convirtiéndolo en algo innecesario y superfluo?, ¿se trata de una desafortunada redacción?, o, por el contrario, ¿es fruto de una decisión muy meditada e intencionada?

Si recordamos las palabras de Pérez Llorca, ponente por UCD, durante la tramitación del texto constitucional en el Congreso ${ }^{4}$, podemos pensar que se refería a la intervención en Cataluña en 1934. En cualquier caso considero que se ha querido configurar la coerción estatal en nuestro sistema constitucional como una reacción que pueda ir más allá del incumplimiento jurídico de unos deberes, incluyendo un cláusula que ofrece un espacio mayor de libertad y discrecionalidad al Gobierno ante supuestos en los que lo principal no es analizar problemas jurídicos, sino enfrentarse desde la óptica del Gobierno central a

4 Véase DSC, núm. 91, de 16 de junio de 1978. 
situaciones que reclaman una respuesta sustancialmente política dentro del marco de la Constitución, pero de la otra Constitución, de la parte ideada para los tiempos de emergencia, aunque la actuación del Gobierno y también del Senado esté sometida a controles políticos y jurisdiccionales a posteriori. En consideración a la inclusión de este supuesto distorsionador se llegó a calificar al 155 como «el artículo más explosivo de la Constitución [...] y exponente expresivo y desafortunado, de esa concepción de la unidad del Estado latente en la formulación del artículo 2, como algo anterior, previo y por tanto, superior a la misma Constitución» (Cruz Villalón, 1981: 687-689).

A mi parecer, nos encontraríamos ante un ejemplo de lo que podríamos denominar razones de Estado constitucionalizadas.

El Tribunal Constitucional ha establecido que el art. 155 diferencia entre los dos supuestos que incorpora: «[...] diferenciación que no debe entenderse como exclusión o contraposición entre ambos. El incumplimiento de concretos deberes constitucionales o legales puede deparar, en según qué casos, lo que también pueda llegar a considerarse un grave atentado al interés general» (STC 89/2019, FJ 4). Afirmando a continuación que el segundo supuesto será abordable desde parámetros jurídicos y no supondría una cláusula general para intervenir discrecionalmente en la autonomía con apreciaciones políticas o de mera oportunidad, sino que evidenciaría el menosprecio por parte de la comunidad autónoma afectada, tanto de la fuerza de obligar de la Constitución como de un principio de lealtad constitucional, concreción de un «deber general de fidelidad a la Constitución» (STC 217/2016, FJ 3).

\section{LAS MEDIDAS CONTENIDAS EN LA PROPUESTA DEL GOBIERNO, APROBADA POR EL SENADO}

El art. 155 de la Constitución incorpora una cláusula general finalista al referirse a las medidas necesarias para el cumplimiento de las obligaciones o la protección del interés general. En tal sentido, en el Acuerdo del Consejo de Ministros de 21 de octubre de 2017 se proponía al Senado para su aprobación un variado conjunto de medidas clasificadas en cinco grandes apartados: las dirigidas al presidente, vicepresidente y Consejo de Gobierno de la Generalitat (A), las dirigidas a la Administración de la Generalitat (B), sobre determinados ámbitos de actividad administrativa (C), al Parlamento (D), y, finalmente, otras de carácter transversal (E).

Es de sobra conocido que dichas medidas fueron aprobadas por el Pleno del Senado de 27 de octubre de 2017, introduciendo modificaciones bastante significativas. 
Respecto al primer grupo, lo más relevante es que incluye nada menos que el cese del presidente y del Gobierno catalanes, y la sustitución en sus funciones por el Gobierno de la nación (conforme al texto modificado por el Senado) o los órganos creados o designados por el Gobierno, correspondiendo al presidente del Gobierno español la disolución anticipada del Parlamento de Cataluña y la convocatoria de elecciones autonómicas, competencia que debería en su caso ejercitarse en un plazo de seis meses y que lo fue mediante el Real Decreto 946/2017, de 27 de octubre, fijándose las elecciones para el 21 de diciembre de 2017.

En relación con la Administración de la Generalitat, categoría que englobaría también a «organismos, entes y entidades vinculadas o dependientes de la misma así como al sector público empresarial», lo más destacable sería la fijación de directrices por parte de los órganos de sustitución, incluyendo la adopción de disposiciones, instrucciones, órdenes..., y el nombramiento o cese de cualquier autoridad, cargo público y personal de la Administración de la Generalitat.

Especial mención merecen las medidas aplicables a determinados ámbitos de la actividad administrativa, como la seguridad y el orden públicos, en el sentido de controlar a los miembros de la policía de la Generalitat de Catalunya - Mossos d'Esquadra - y permitir el despliegue de las fuerzas y cuerpos de seguridad del Estado con la posibilidad de sustituir a los Mossos.

En el ámbito económico, financiero, tributario y presupuestario se pretendía garantizar la prestación de los servicios públicos esenciales, la estabilidad presupuestaria y la sostenibilidad financiera, y controlar, asimismo, que ni los fondos transferidos por el Estado a la comunidad autónoma ni los ingresos recaudados por esta se destinasen a actividades o fines relacionados con el proceso secesionista.

Un mes antes de la aprobación del acuerdo se habían utilizado las medidas coercitivas previstas en la LO 2/2012, mediante un desarrollo reglamentario con la Orden HFP/878/2017, de 15 de septiembre, para justificar una verdadera intervención de las cuentas económicas de la Generalitat catalana a través de un mecanismo de sustitución que, a mi parecer, se apartaba de lo dispuesto en el art. 26 de la mencionada Ley Orgánica 2/2012, y que, por ello, sería ilegal, si bien podría estar justificado con la cobertura de la aplicación del art. 155, pero no sin él o antes de que entrase en vigor.

La sentencia del Tribunal Supremo 1528/2018, de 23 de octubre, se manifestó en un sentido contrario entendiendo que no era necesario seguir el procedimiento del art. 155 y que se pueden adoptar medidas de intervención económica como las aprobadas por el acuerdo impugnado.

Se descarta que el único cauce posible para adoptar medidas sea el recogido en los artículos 25 y 26 de la Ley Orgánica 2/2012. La obligación de cumplir los 
acuerdos y disposiciones que se adopten en desarrollo del FLA (Fondo de Liquidez Autonómico) ampara mecanismos de control y consecuencias caso de incumplimiento de sus obligaciones, debiendo resaltarse que aquí se parte de una situación de hecho de incumplimiento del Plan de ajuste de la Comunidad (FJ 6).

El acuerdo alude, asimismo, a que los órganos o autoridades creados por el Gobierno ejerzan por sustitución las funciones de la Generalitat en materia de telecomunicaciones, servicios digitales y tecnología de la información. Es muy relevante que el párrafo incluido en el acuerdo sobre el servicio público autonómico de comunicación audiovisual (TV3...), en el que se mencionaba la garantía de una información veraz, objetiva y respetuosa con el equilibrio territorial y el conocimiento y respeto de los valores y principios contenidos en la Constitución y en el Estatuto de Autonomía, fuese eliminado por el Senado de la redacción definitiva.

Las medidas dirigidas al Parlamento suponían una auténtica intervención y control de este, aunque la decisión inmediata del presidente del Gobierno de disolverlo y convocar nuevas elecciones significó un rotundo cambio de estrategia. Por otro lado, el Senado eliminó del texto finalmente por él aprobado, y por considerarlos contrarios a la Constitución, dos párrafos que encomendaban a una autoridad designada por el Gobierno el control y supervisión de importantes actuaciones parlamentarias.

No obstante, continúa en el acuerdo la prohibición, mientras las medidas se mantengan vigentes, de proponer candidato a la Presidencia de la Generalitat y de celebrar debate y votación de investidura. Asimismo, se impide el control parlamentario de la actuación de las autoridades encargadas de ejecutar las medidas aprobadas por el Senado, si bien se establece que el control de estas corresponderá exclusivamente al órgano que designe a tal efecto el Senado. En el Acuerdo del Senado de 27 de octubre de 2017 se incluyó un nuevo apartado (g), en el que, respetando las competencias de control de la acción del Gobierno que la Constitución encomienda al Congreso de los Diputados, se afirma lo siguiente: «Sin perjuicio de lo establecido en el artículo 66.2 de la Constitución, las facultades de seguimiento y control de las medidas contenidas en el acuerdo se atribuyen a la Comisión conjunta de las Comisiones General de Comunidades Autónomas y Constitucional».

Finalmente, el Acuerdo del Consejo de Ministros incluía una serie de medidas a las que se calificaba de carácter transversal, con referencias a cuestiones como la normativa aplicable y la revisión jurisdiccional de los actos y disposiciones dictados por sustitución, la invalidez e ineficacia de actuaciones autonómicas que contravinieran las medidas aprobadas en el Acuerdo, la publicación en boletines oficiales, las modificaciones de las estructuras y 
organismos de la Generalitat de Cataluña, la potestad disciplinaria... Sí me parece importante indicar que las medidas contenidas en el Acuerdo del Consejo de Ministros se mantendrían vigentes hasta la toma de posesión de un nuevo Gobierno de la Generalitat resultante de la celebración de las correspondientes elecciones, lo que no sucedió hasta el 2 de junio de 2018, y que el Gobierno podría anticipar el cese de tales medidas dando cuenta al Senado o plantear ante el Senado modificaciones o actualizaciones de las medidas inicialmente autorizadas (E.9) (Gómez Orfanel, 2018: 1644-1646).

En el Acuerdo del Pleno del Senado se añadía, además, que el Gobierno «llevará a cabo una utilización proporcionada y responsable de las medidas aprobadas por el Senado, modulando su aplicación si se produjeran cambios en la situación u otras circunstancias que así lo aconsejen» (E.9.).

En una reciente e interesante monografía (Nieto Jiménez, 2020: 140-144 y 240) se han clasificado las medidas conforme a criterios procedimentales y modo de aplicabilidad por el Gobierno en tres apartados. En el primero se situarían las que respetan la estructura del procedimiento Gobierno-Senado-Gobierno, en el segundo, las que se implementan automáticamente cuando el Gobierno ha adoptado alguna de las del primer grupo, y, finalmente, aquellas que no dependen de actos de adopción gubernamentales, es decir, que serían autoaplicativas, implementándose de hecho por la aprobación del Acuerdo del Senado, y entre ellas se encontrarían las dirigidas al Parlamento catalán (D.1, D.2 y D.3). A partir de la publicación del acuerdo en el $B O E$ estas medidas entrarían automáticamente en vigor, mientras que las de los dos primeros grupos lo harían desde el momento en el que el Gobierno, habilitado por el Senado, decidiera «adoptarlas». Estas consideraciones del mencionado autor estarían al servicio de la posición, discutible sin duda, que mantiene respecto a que "hasta el último momento se deja en manos del Gobierno la decisión de no desplegar la coerción en sentido estricto, de no ejecutar las medidas aprobadas por el Senado, en fin, de agotar las posibilidades que la negociación y el diálogo puedan ofrecer hasta el final» (143). Por otra parte, no olvidemos que, con independencia del control parlamentario que continúe ejerciendo el Congreso de los Diputados, el Senado, y más en concreto la Comisión Conjunta, dispone de facultades de control de las medidas.

García Torres (2019a: 130 y 163), de una manera menos radical, se ha pronunciado sobre las posibilidades de desistimiento de la vía coercitiva por parte del Gobierno a lo largo del procedimiento que se inicia con el requerimiento y finaliza con la aprobación del Senado, si bien afirma que debe reconocerse al Gobierno «la potestad de poner fin a la situación coercitiva excepcional cuando lo crea políticamente justificado». 
La aplicación del art. 155 a Cataluña se realizó con un Senado que aprobó por una gran mayoría, expresión de un amplio apoyo político, las medidas propuestas por el Gobierno, aunque incluyendo algunas modificaciones. Parece lógico pensar en la conveniencia de unas voluntades convergentes entre ambos órganos constitucionales para activar el art. 155. Puede darse el caso de un Gobierno con suficiente apoyo parlamentario en el Congreso y que carezca de mayoría en el Senado o que incluso se encuentre frente a una mayoría absoluta opuesta en dicha Cámara. En tal supuesto sería difícilmente asumible que ese Senado modificase sustancialmente la propuesta del Gobierno y que este resultase obligado a ejecutar tales medidas sin que pudiese desistir de la ejecución de las medidas aprobadas o supeditando el cese de estas a la explícita aprobación del Senado.

Las medidas propuestas en su momento por el Gobierno y aprobadas por el Senado supusieron una consideración multidireccional y sistemática del art. 155 que sería avalada posteriormente por el Tribunal Constitucional. El Acuerdo del Consejo de Ministros puede ser calificado de duro, aunque fuese dulcificado luego por el Senado. Intentaba dar una respuesta a un gran desafío, a un incumplimiento global de obligaciones jurídicas, a un ataque a la Constitución encarnado en una declaración unilateral de independencia y, especialmente, al hecho de que la Ley 20/2017 del Parlamento de Cataluña, de transitoriedad jurídica y fundacional de la República, pretendía asumir la totalidad de unas nuevas competencias estatales (Gómez Orfanel, 2018: 1644).

\section{LA EJECUCIÓN DE LAS MEDIDAS}

La ejecución de las medidas se llevó a cabo mediante diversas normas emanadas del Gobierno y adoptadas algunas el mismo día en que se publicó el Acuerdo del Pleno del Senado aprobando las medidas requeridas por el Gobierno. Los reales decretos 942/2017 y 943/2017, de 27 de octubre, dispusieron los ceses del presidente de la Generalitat de Cataluña, del vicepresidente y de los consejeros, que serían sustituidos en todas sus funciones por el Gobierno del Estado o los órganos creados por este, y en tal sentido hay que considerar como muy relevante el RD 944/2017, de 27 de octubre, en el que se designa al presidente, vicepresidenta, Consejo de Ministros y ministros del Estado como órganos habilitados para la efectiva aplicación de las medidas, incorporando un anexo donde se especifican las competencias y funciones que se atribuyen a los diversos ministerios en sustitución de las competencias que ejercían las estructuras catalanas, y, además, con la facultad de impartir 
instrucciones con carácter jerárquico y de dirección a órganos administrativos y empleados públicos. Recordemos que el Senado había modificado el Acuerdo del Consejo de Ministros, que no incluía al propio Gobierno de la nación como órgano de sustitución de competencias de la Generalitat (grupo A de medidas, párrafo tercero).

Toda la Administración de la Generalitat quedaba sometida al control del Estado. Por otro lado, el RD 943/2017 incluía el cese de todo el personal eventual adscrito a los miembros del Gobierno catalán: en torno a unas 140 personas, una proporción importante en relación con los alrededor de 250 cesados durante la aplicación del art. 155.

Además de la destitución del Gobierno catalán, el Acuerdo del Senado otorgaba al presidente del Gobierno del Estado las facultades del presidente de la Generalitat para disolver anticipadamente el Parlamento y convocar elecciones autonómicas en un plazo máximo de seis meses.

El RD 945/2017, de 27 de octubre, suprimía diversos órganos de la Generalitat de gran importancia para el proceso de independencia de Cataluña, como las oficinas del presidente y vicepresidente, el Consejo Asesor para la Transición Nacional (posteriormente Instituto de Estudios de Autogobierno), la Comisión especial sobre la violación de derechos fundamentales en Cataluña, el Patronato Cataluña Mon-Consejo de Diplomacia Pública de Cataluña (DIPLOCAT), y las delegaciones del Gobierno de la Generalitat en doce países (Francia, el Reino Unido, Alemania, Italia, Estados Unidos...) y ante organizaciones internacionales con sede en Ginebra, París, Viena y Estrasburgo. Asimismo, se cesaba a diversos cargos públicos, como el delegado del Gobierno en Madrid, el representante permanente ante la Unión Europea y el director general de la policía catalana.

Otro real decreto, el 954/2017, de 31 de octubre, disponía la supresión de instituciones y cese de sus titulares (Secretaría y Comisión Interdepartamental para el desarrollo del Autogobierno, Oficina para la mejora de las instituciones del Autogobierno). Incluyendo, además, una lista de nueve altos cargos (entre los que figuraba el catedrático y exvicepresidente del Tribunal Constitucional, Carles Viver Pi-Sunyer en cuanto que director del Instituto de Estudios del Autogobierno), a quienes se cesaba junto con todo el personal eventual adscrito.

Especial trascendencia tendría la OM INT/1038/2017, de 28 de octubre, de cese de Josep Lluís Trapero en la plaza de mayor de la Escala Superior de Mossos d'Esquadra, siendo nombrado para tal puesto Ferrán López, que ocupaba el segundo lugar en la cúpula de dicho cuerpo.

A título de ejemplo, señalo algunos de los nuevos nombramientos realizados por el Gobierno: 
- Real Decreto 983/2017, de 10 de noviembre, de nombramiento de directora general de Modernización de la Administración de Justicia de la Generalitat.

- Real Decreto 990/2017, de 17 de noviembre, de nombramiento de director general de Centros Concertados y Privados de la Generalitat.

- OM ECD/1142/2017, de 22 de noviembre, de nombramiento de presidente del Consejo de Dirección del Consorcio de Educación de Barcelona.

El Real Decreto 946/2017, de 27 de octubre, declaró la disolución del Parlamento de Cataluńa y la convocatoria de elecciones para el 21 de diciembre de 2017. En realidad, el enunciado de tal disposición se refería primero a la convocatoria y luego a la disolución, lo que no parece desde luego muy correcto. La disolución se efectuaba a propuesta del presidente del Gobierno sustituyendo al de la Generalitat, previa deliberación del Consejo de Ministros y en virtud de lo dispuesto en los arts. 65 y 75 del Estatuto de Autonomía de Cataluña.

El Real Decreto 953/2017, de 31 de octubre, reguló diversos elementos del proceso electoral y de las subvenciones y el control de la contabilidad electoral.

Disuelto el Parlamento, su Diputación Permanente pasó a ejercer las funciones encomendadas por el Estatuto de Cataluña, las leyes y el propio Reglamento del Parlamento, y la Mesa de la Diputación Permanente, las funciones de la Mesa del Parlamento, declarando caducados todos los trámites pendientes de examen y resolución correspondientes a la legislatura disuelta, salvo aquellos cuya continuidad se establecía por leyes específicas y los que debía conocer la Diputación Permanente y que figuraban en los correspondientes anexos del Acuerdo de la Mesa de la Diputación Permanente de 15 de noviembre de 2017. Respecto a las iniciativas legislativas, quedaron decaídas 46, correspondiendo 9 a proyectos de ley y 36, a proposiciones de ley.

\section{EL GRAN DEBATE: LA LEGITIMIDAD CONSTITUCIONAL DEL CESE DEL GOBIERNO Y DE LA DISOLUCIÓN DEL PARLAMENTO}

En síntesis, las posiciones se han agrupado en torno a si las «medidas necesarias» recogidas en el 155.1 tienen que limitarse a "dar instrucciones» o si, por el contrario, el artículo debe interpretarse como una cláusula de apoderamiento general, incluso de plenos poderes, y dotada de una amplia discrecionalidad, aunque sometida a ciertos límites que no impedirían la 
posibilidad de cesar Gobiernos, disolver Parlamentos y convocar elecciones. Es decir, un enfoque minimalista de la coerción estatal frente a otro que permitiría desplazar e inaplicar normas estatales, autonómicas, e incluso constitucionales.

$\mathrm{Al}$ primero se acogen los sectores independentistas y partidarios de la autodeterminación, mientras que, al segundo, el Gobierno y los grupos políticos que le apoyaron en octubre de 2017, y gran parte de la doctrina constitucionalista.

En el recurso de inconstitucionalidad presentado por el Parlamento catalán o, siendo precisos, por su Diputación Permanente, se afirmaba textualmente:

[...] del debate constituyente y de las aproximaciones doctrinales más relevantes se deduce claramente que el artículo $155 \mathrm{CE}$, que no precisa el alcance de las medidas a adoptar, se limita a describir una técnica —el poder de dar instrucciones a las autoridades autonómicas-, sin referirse en ningún caso a la posibilidad de suspender o disolver órganos autonómicos ni a la posibilidad de que la intervención del poder central se concrete en el cese de cargos de los órganos de la comunidad autónoma (pp. 36-37 del recurso).

Dicho recurso aparece firmado por Joan Ridao Martín, quien, a su vez, es autor de un texto que coincide notablemente con el contenido de aquel (2018: 189-193). En esta línea podemos situar también a Albertí (2018: 16-19) y a Vintró (2019: 96-100), entre otros. Gran parte de sus argumentos quedarían reflejados en los recursos planteados ante el Tribunal Constitucional y especialmente en el del Parlamento catalán, aunque muchas de sus alegaciones coincidían con el presentado por los diputados del grupo Unidos Podemos. En lo tocante a las medidas aprobadas en aplicación del 155 y que afectaban al cese del Gobierno y disolución parlamentaria, se argumentaba que vulneraban contenidos constitucionales o del bloque de la constitucionalidad, como el principio de autonomía (art. $2 \mathrm{CE}$ ), el gobierno parlamentario de las comunidades autónomas (art. $152 \mathrm{CE}$ ), la naturaleza y función constitucional del estatuto de autonomía (art. $147 \mathrm{CE}$ ) y también derechos fundamentales, sobre todo del art. 23.2, en lo referente a la vulneración del ius in officium de los cargos públicos, y del $24 \mathrm{CE}$, en cuanto a la vulneración del derecho al juez ordinario predeterminado por la ley al producirse la pérdida del aforamiento. En relación con el Estatuto de Cataluña se consideraban atacados, entre otros, los arts. 67 y 68, referidos al presidente de la Generalitat y al Gobierno, 55, funciones del Parlamento, 58, autonomía parlamentaria, 70, fuero procesal, 74, responsabilidad política del Gobierno... 
Asimismo, se argumentó (p. 60 del recurso) que la medida del cese de los miembros del Gobierno no era proporcional y se configuraba como una sanción. Recordemos que en el Acuerdo del Gobierno aprobado por el Senado se afirmaba, por el contrario, que las medidas adoptadas «son las absolutamente necesarias y proporcionadas al fin que se adoptan y tendrán la duración temporal que se entiende necesaria para reponer el marco constitucional y estatutario vulnerado [...] puesto que de ningún modo tienen por objetivo suspender la autonomía de Cataluña, sino precisamente salvaguardar y restaurar la aplicación de su Estatuto de Autonomía como parte del orden constitucional». Más adelante se justificaba que las medidas tenían como destinatarios al Gobierno y Parlamento de Cataluña, ya que «han sido ambas instituciones las que a lo largo de este tiempo han incumplido el orden constitucional de manera reiterada y progresiva, haciendo caso omiso a los distintos pronunciamientos y requerimientos del Tribunal Constitucional» (D. Objetivo y necesidad de las medidas del artículo 155).

En opinión de Vintró (2019: 81-83), un importante sector de la doctrina española consideraba en principio que las medidas aplicables conforme al 155 venían a coincidir con las de la doctrina alemana interpretadora del contenido del art. $37 \mathrm{LF}$, es decir, la ejecución sustitutoria y la presión financiera, entre otras, citando como ejemplo a Vírgala (2005: 100-101), Satrústegui (2017: 1886-1888), De la Quadra-Salcedo (2018: 41-44) y Álvarez Álvarez (2018: 603-605). Pero hay que tener en cuenta que en Alemania, a diferencia que en España, no se contempla el grave atentado al interés general como presupuesto para aplicar la coerción federal. Significativamente incluye, por otro lado, a Cruz Villalón (1984: 60) y, sobre todo, a De la Quadra-Salcedo (2018: 46) como favorables al empleo de cualquier medida coercitiva que no suponga derogar el Estatuto o suspender indefinidamente la autonomía, por lo que, en consecuencia, sería legítimo cesar a un Gobierno o disolver un Parlamento. Recientemente, tal opción ha sido apoyada expresamente con otro tipo de argumentos por García Roca (2019a: 225-230) y también por Freixes Sanjuán, quien añadía su crítica a que las medidas aprobadas «no habían incidido en absoluto en los dos grandes ejes del secesionismo: la educación y la comunicación» (2019: 36).

No es este el lugar adecuado para realizar un comentario sistemático de las trascendentales y complejas sentencias 89/2019 y 90/2019, pero parece oportuno incluir algunas consideraciones que el propio órgano jurisdiccional consideró como fundamentales.

El Tribunal Constitucional estima necesarias las medidas adoptadas, y, en tal sentido, por lo que respecta al cese «del Presidente de la Generalitat, del Vicepresidente y de los Consejeros que integran el Consejo de Gobierno", se 
considera que tal medida está justificada dada la voluntad de la Presidencia y del Gobierno de la Generalitat «de situarse al margen de la Constitución, del propio Estatuto de Autonomía y del ordenamiento en su conjunto, a fin de constituir, a lo largo de un proceso al margen de cualquier norma y con menosprecio de toda lealtad constitucional, un estado independiente en forma de república» (STC 89/2019, FJ 12).

En cuanto a la disolución del Parlamento acordada por el presidente del Gobierno en aplicación de lo decidido por el Senado, el Pleno recuerda que «si un parlamento autonómico llevase a cabo actuaciones que incumpliesen obligaciones constitucionales o legales o atentasen gravemente al interés general de España, la concreción de lo necesario para retornar al cumplimiento constitucional o restablecer el interés general puede también referirse a la asamblea legislativa». Y, en el caso concreto el Tribunal, citando sentencias y autos dictados en relación con actos y decisiones de la Cámara autonómica, constata que «el Parlamento de Cataluña no ha resultado en absoluto ajeno a los hechos que han desencadenado la aplicación del procedimiento del art. 155" (STC 89/2019, FJ 13) —véase como ejemplo de síntesis del contenido de las sentencias la Nota Informativa 89/2019 del Tribunal Constitucional-.

\section{ALGUNAS REFERENCIAS SOBRE LA APLICACIÓN DE LAS MEDIDAS}

\section{LA POSICIÓN DEL GOBIERNO EN LAS COMPARECENCIAS ANTE LA COMISIÓN CONJUNTA DEL SENADO}

En el Acuerdo del Pleno del Senado de 27 de octubre de 2017 se aludía a que con una periodicidad de dos meses el Gobierno daría cuenta al Senado del estado de aplicación y ejecución de las medidas (E.9), concretándose, además, que, «sin perjuicio de lo establecido en el artículo 66.2 de la Constitución, las facultades de seguimiento y control de las medidas contenidas en el Acuerdo se atribuyen a la Comisión Conjunta de las Comisiones General de Comunidades Autónomas y Constitucional» (II g). El 4 de diciembre de 2017, 38 días después, compareció el secretario de Estado para las Administraciones Territoriales, Roberto Bermúdez de Castro, para informar acerca del desarrollo y ejecución de las medidas aprobadas por el Senado al amparo del art. 155 de la Constitución (Diario de Sesiones del Senado, de 4 de diciembre de 2017, núm. 202, pp. 2 y ss.). En su intervención reiteró que las medidas de coerción aprobadas perseguían cuatro objetivos conforme a lo dispuesto en el mencionado acuerdo: restauración de la legalidad constitucional y estatutaria, asegurar la neutralidad institucional, mantener el bienestar social y recuperar 
el crecimiento económico, y asegurar los derechos y libertades de todos los catalanes, pasando revista, a continuación, a lo que denominó el desarrollo en la práctica del art. 155: ceses y supresión de órganos, fluidez y respeto institucional entre la Administración General del Estado y la autonómica, normalización de la gestión administrativa de la Generalidad, siete Consejos de Ministros celebrados sobre la situación en Cataluña y logros conseguidos en diversos sectores. En síntesis, balance satisfactorio, lo cual sería criticado posteriormente por algunos senadores intervinientes en la sesión de control.

Pocos días después, el 18 de diciembre, compareció en el mismo escenario la vicepresidenta del Gobierno y ministra de la Presidencia y para las Administraciones Territoriales, Soraya Sáenz de Santamaría, quien, tras justificar la necesidad y conveniencia de la intervención estatal5, realizó una crítica multidireccional del independentismo, generador de incertidumbre, estableciendo planes sin opción de cumplirse, incapaz de conseguir prosperidad, enfrentando a los catalanes..., y glosando a continuación la convocatoria de elecciones del 21 de diciembre que se celebrarían "con completa legalidad, legitimidad y libertad» para elegir un nuevo Parlamento, «generador de un

5 «Señorías, el Estado reaccionó asumiendo su obligación frente a los que incumplían reiteradamente las suyas. Reaccionó con la única respuesta posible: la ley y la política. Porque fuimos capaces todos de alcanzar un gran acuerdo entre los partidos que defendemos la convivencia constitucional para asegurar su plena vigencia; un gran acuerdo que se vio reforzado en esta Cámara con el apoyo de más del $80 \%$ de los senadores y nueve partidos. Juntos acordamos que una situación tan excepcional demandaba una solución extraordinaria: la aplicación constitucional del mecanismo de garantía del Estado de las Autonomías, el artículo 155. Una solución no imprevista, porque los constituyentes nos dotaron de todas las herramientas para defender el Estado de derecho que con tanto esfuerzo trataban de construir; pero sí inédita, porque nunca un Gobierno autonómico había llegado tan lejos ni había hecho tanto daño. Nunca una autonomía había decidido situarse absolutamente al margen de la Constitución que la ampara y en contra del estatuto que la regula. Nunca una institución democrática se había atrevido a cuestionar la democracia misma para reclamar derechos que no existen y no asumir así las obligaciones que le corresponden. Nunca un Gobierno, que debe estar al servicio de todos los ciudadanos, había despreciado de forma tan clara a una gran parte de ellos, a todos los catalanes a los que no reconocía y no asumía representar. Esa era la realidad y esos fueron precisamente los objetivos que acordamos fijarnos en la aplicación del artículo 155: restaurar el respeto a la legalidad constitucional y estatutaria, a la neutralidad institucional, a los derechos de los ciudadanos y al interés general. A esa voluntad de crecer, crear empleo y generar bienestar que comparte cualquier sociedad avanzada. Por tanto, el objetivo de un mecanismo tan extraordinario ha sido y es sencillamente volver a la normalidad» (DSS, núm. 207, p. 3). 
nuevo Gobierno cuya función prioritaria ha de ser cumplir la ley, porque el reiterado incumplimiento de la ley y la declarada desobediencia a los tribunales fue la causa de desgobierno de Cataluña y, por tanto, del cese de sus responsables» (DSS, de 18 de diciembre de 2017, núm. 207, pp. 2 y ss.).

El 22 de marzo de 2018, celebradas ya las elecciones al Parlamento catalán y constituido este, tuvo lugar en el Senado una nueva comparecencia del citado secretario de Estado de Administraciones Territoriales para dar cuenta del desarrollo y ejecución de las medidas aprobadas por el Senado (DSS, de 22 de marzo de 2018, núm. 254, pp. 4 y ss.). En su opinión, la aplicación del 155 habría permitido el regreso a la normalidad dando a la Administración pública el impulso perdido, subrayando la colaboración de la gran mayoría de empleados públicos y destacando a continuación los objetivos sectoriales alcanzados (sanidad, educación, empleo público, seguridad, infraestructuras...), y ofreciendo una visión notablemente triunfalista ${ }^{6}$.

\section{LA PERSPECTIVA SOBERANISTA}

A continuación mencionaré diversas referencias documentales asociables con fuentes de información situadas en una posición independentista o soberanista y procedentes de instituciones de la Generalitat o que actúan bajo su influencia.

La Revista catalana de dret públic dedicó en 2019 un número especial a la aplicación del art. $155 \mathrm{CE}$ a Cataluña en el que se incluía en catalán, y traduciendo a dicha lengua la denominación en los índices de documentos en castellano, un interesante, completo y útil dosier sobre el tema (Martín i Alonso, 2018), en cuya introducción se indica que la documentación, cerrada a fecha de 12 de marzo de 2019, se estructura en nueve apartados: normativa y doctrina constitucional; procedimiento para la aplicación del art. $155 \mathrm{CE}$ a la Generalitat de Cataluña; las medidas adoptadas por las instituciones estatales (la cursiva es mía); los estudios de carácter público y posiciones mantenidas sobre

6 «Con todo, el mejor argumento que avala la gestión que hemos hecho al frente de la Administración ha sido la poca prisa que, hasta ayer, se estaban dando en relevarnos. Hasta el mismo momento en que llegue este relevo, el Gobierno va a seguir actuando con la misma lealtad, con el mismo rigor y con renovados esfuerzos. Eso es también lo que se tiene que exigir al próximo Gobierno de Cataluña, que cumpla sus obligaciones de legalidad, de neutralidad, de transparencia y de interés general. Esto es lo que deben garantizar las fuerzas políticas que dicen disponer de mayoría para gobernar». 
la aplicación del art. 155 CE y las medidas adoptadas bajo su cobertura (la cursiva es mía); los procesos constitucionales; los procesos contenciosos administrativos; el procedimiento de investidura del presidente de la Generalitat de Cataluña; el nombramiento y la toma de posesión de los miembros del Gobierno de Cataluña, y, por último, la doctrina sobre el art. 155 CE.

Desde la perspectiva con que escribo estas páginas, el apartado que más me ha interesado ha sido el tercero, referido a las medidas adoptadas por las instituciones estatales respecto al autogobierno de Cataluña (Mesures adoptades per les institucions estatals respecte de l'autogovern de Catalunya a l'empara de l'article 155 CE).

No me resisto a indicar las subdivisiones sistemáticas, y, a su vez, subdivididas, que integran dicho apartado y que contribuyen, sin duda, a facilitar la información o documento que se pretenda obtener?

Además, el mencionado autor del dosier ha publicado en los últimos años diversos trabajos de indudable interés, y el 5 de septiembre de 2018 firmaba, en cuanto que cap de l'Area d'Assessorament sobre l'Organització Territorial del Poder, una publicación autónoma editada por el Institut d'Estudis de l'Autogovern en la que ampliaba contenidos del citado dosier (Martín i Alonso, 2018).

En noviembre de 2018, el Commissionat per al Desplegament de l'Autogovern (Generalitat de Catalunya, Departament de la Présidencia) editó un amplio y pluridisciplinar documento sobre los efectos de la intervención estatal sobre la Generalitat de Cataluña mediante el art. 155 desde el momento de su puesta en marcha hasta el nombramiento de los integrantes del Gobierno catalán (el presidente había sido investido en fecha anterior) el 1 de junio de 2018 (Commissionat per al Desplegament de l'Autogovern, 2018).

Una aportación importante para conocer la situación de la vigencia del art. 155 desde la perspectiva catalanista oficialista es la de Bernardi i Gil, director general de Dret i d'Entitats Juridiques del Departament de Justicia de la Generalitat y profesor de Derecho administrativo en la Universidad Pompeu

\subsection{Ceses.}

3.2. Supresión de órganos.

3.3. Designación de órganos y nombramiento de cargos de carácter político, eventual o de libre designación .

3.4. Convocatoria de elecciones y disolución del Parlamento de Cataluña.

3.5. Normas y medidas financieras y presupuestarias.

3.6. Normas en los sectores ambiental, local y de función pública.

3.7. Sistematización de las medidas y decisiones adoptadas por las instituciones y cargos estatales al amparo del art. $155 \mathrm{CE}$, en diversos ámbitos materiales. 
Fabra, que ofrece una visión crítica y bastante elaborada de la aplicación de las medidas y de sus efectos. En su opinión, los ceses del presidente, del Gobierno y del personal eventual, así como la supresión de diversas entidades y la intervención de la Administración de la Generalitat, sometida al control a distancia de órganos estatales, además de suponer medidas desproporcionadas y vulneradoras de principios constitucionales y derechos fundamentales (autonomía, participación política y tutela judicial efectiva, junto con principios estructurales del derecho público, como seguridad jurídica, interdicción de la arbitrariedad, objetividad, legalidad y eficacia), habrían paralizado la actividad normativa y generado indefensión jurídica y la ineficiencia de la actividad administrativa, «orientada a la simple gestión ordinaria de los servicios y a atender los requerimientos de información y las instrucciones estatales» (Bernardi i Gil, 2019: 22-23).

Me ha parecido oportuno aludir también a los informes realizados por la asociación Servidors Públics de Catalunya, concretamente los publicados bajo la denominación de Inventari de danys.

En concreto, se trata de cuatro informes (de 1 de diciembre de 2017, 19 de diciembre de 2017, 25 de febrero de 2018 y 18 de mayo de 2018) críticos con la intervención estatal.

En el cuarto informe, de más de 120 páginas, se recogen los siguientes datos, que se personalizan o desarrollan en el contenido de este y que traslado al castellano:

\begin{tabular}{lr}
\hline Personas en el exilio & 7 \\
Detenidos y en prisión & 25 \\
Personas cesadas & 259 \\
Organismos suprimidos o disueltos & 24 \\
Organismos intervenidos & 4 \\
Iniciativas normativas decaídas & 108 \\
Nombramiento de cargos por el Gobierno & 12 \\
Afectaciones en la contratación & 92 \\
Actividades canceladas o suspensas & 15 \\
Líneas de subvención paralizadas & 25 \\
Pérdida de oportunidades económicas & 9 \\
\hline
\end{tabular}

Parece conveniente citar también la constitución el 6 de noviembre de 2018, y en el Parlamento catalán, de la Commissió d'Investigació sobre l'Aplicació de l'Article 155 de la Constitució Espanyola a Catalunya, que tenía por objeto «analizar los efectos de la aplicación del artículo 155 de la Constitución 
española [...] así como las causas que la motivaron, la adecuación de tal aplicación a la legalidad, el carácter de las medidas adoptadas y sus consecuencias y la valoración de los daños y las posibles responsabilidades por la aplicación de tal artículo» (Resolución 24/XII del Parlamento de Cataluña, publicada en el Boletín Oficial del Parlamento de Cataluña, núm. 121, de 9 de julio de 2018).

\section{LA DECISIÓN DEL TRIBUNAL CONSTITUCIONAL SOBRE LAS MEDIDAS APROBADAS Y SU EJECUCIÓN}

El Tribunal Constitucional ha avalado claramente dichas medidas y no ha considerado que haya motivos de inconstitucionalidad salvo en lo referente a determinados supuestos de publicación en boletines oficiales (párrafo segundo del apartado E.3). Por otro lado, limita el objeto de su examen al contenido impugnado del Acuerdo del Pleno del Senado del 27 de octubre de 2017, al que se considera dotado de fuerza de ley, desestimando la pretensión de los recurrentes de incluir también "todas las disposiciones que se han dictado sin solución de continuidad en desarrollo o como complemento o adición de las medidas aprobadas por el referido Acuerdo» (STC 90/2019, FJ 1).

La técnica jurídica empleada para legitimar las medidas adoptadas y rechazar las correspondientes alegaciones de los recurrentes sería la de considerar el art. 155 no como un fin sino como un instrumento para restaurar el orden constitucional en determinados supuestos y a través de un procedimiento previsto y que ofrecería cobertura suficiente para «excepcionar el ordenamiento jurídico» (STC 89/2019, FJ 14), y, más en concreto, posibilitar con límites «la constricción de la autonomía [...] y la inaplicación excepcional de normas estatutarias y legales y su desplazamiento temporal por las reglas mediante las que la Cámara, a propuesta del Gobierno, determine las medidas concretas a adoptar por el ejecutivo" (STC 89/2019, FJ 2), que no actuaría estrictamente como tal (art. $97 \mathrm{CE}$ ) ni con títulos competenciales sino como «órgano constitucional garante de la integridad de la norma suprema del ordenamiento y del orden territorial que de ella deriva» (STC 90/2019, FJ 6). Es decir, como un auténtico defensor de la Constitución, pues hay que tener en cuenta, además, la «posición prevalente del Gobierno en orden a la salvaguarda del sistema constitucional» (STC 215/2016, FJ 11).

$\mathrm{Al}$ interpretar lo que deban considerarse medidas necesarias, y ello en mi opinión puede sorprender, el Tribunal Constitucional establece que no tienen que ser medidas proporcionadas en el sentido de «menos gravosas» y "graduales», argumentando que el principio de proporcionalidad resulta aplicable en el ámbito de los derechos fundamentales pero que no tiene un carácter 
autónomo como criterio de constitucionalidad. El eje Gobierno-Senado dispondría de un amplio margen de discrecionalidad y apreciación sobre la necesidad de tales medidas, aunque sometido al control jurídico del Tribunal que juzgaría «no la medida en sí, sino el juicio que han realizado otros órganos constitucionales, el Gobierno y el Senado acerca de la adecuación de la medida a las circunstancias que han desencadenado la aplicación del art.155 CE» (STC 89/2019, FJ 11).

Comentando las sentencias, García Roca (2019b: 515-518) ha destacado críticamente este desplazamiento del principio de proporcionalidad por un criterio de razonabilidad al que califica de impreciso, indeterminado, con menos garantías y más laxo, mientras que el de proporcionalidad está vinculado con conceptos fundamentales como el Estado de derecho y la democracia constitucional, y supone un criterio habitual y generalizado de interpretación constitucional que sigue siendo aplicado por los tribunales más relevantes y no solo en el ámbito de los derechos fundamentales, y que sería incluso consustancial a la idea del derecho. Sí estaría de acuerdo con el carácter externo del control en el sentido de no sustituir el juicio político sobre la necesidad y adecuación finalista de las medidas que correspondería al Gobierno y al Senado. Lo que estaría encomendado al Tribunal Constitucional sería evitar que se traspasaran los límites jurídicos fundamentales, impedir los excesos.

Una vez explicada su posición, el Tribunal Constitucional abre el camino en la STC 89/2019 para analizar las medidas en concreto en los fundamentos jurídicos siguientes, referidos al cese y sustitución del Gobierno catalán (12), a la disolución del Parlamento autonómico (13), a la Administración de la Generalitat (14), e incluso a la policía de la Generalitat (15).

No me parece tan «temperada» la visión ofrecida por García Roca en su comentario de las sentencias 89 y 90/2019. El Tribunal Constitucional ha avalado un temible y multidireccional $155 \mathrm{CE}$ a pesar de los límites trazados y la necesidad de responder al desafío lanzado por el soberanismo catalán. Excepcionar el ordenamiento jurídico inaplicando, temporalmente eso sí, normas estatales y autonómicas, y opino que también afectando a preceptos constitucionales. Ello ha estado compensado por una previsible corta duración, que se ha extendido, no obstante, desde el 27 de octubre de 2017 al 2 de junio de 2018. El 155 en aplicación ha despertado, en parte, una nueva Constitución. Si el famoso y curioso jurista persa recordado por Pedro Cruz Villalón (1999) nos hubiese visitado en ese período para conocer nuestra Constitución, bloque de constitucionalidad y resto del ordenamiento jurídico, poco provecho habría obtenido sin la lectura y estudio profundo de unos textos tan complejos y trascendentales como el del del Pleno del Senado de 27 de octubre, que incluía la aprobación y también modificación de las medidas 
propuestas por el Gobierno en su Acuerdo del 21 de octubre de 2017, de abundantes y variadas opiniones doctrinales y de las dos sentencias mencionadas del Tribunal Constitucional.

\section{Bibliografía}

Aja, E. y Tornos, J. (1985). El sistema jurídico de las comunidades autónomas. Madrid: Tecnos. Albertí Rovira, E. (2018). Cuestiones constitucionales en torno a la aplicación del artículo 155 en el conflicto de Cataluña. Revista d'estudis autonómics i federals, 27,1-23. Disponible en: https://doi.org/10.22201/iij.24484881e.2017.36.10869.

Álvarez Álvarez, L. (2016). La coerción estatal del artículo 155 CE en la estructura del Estado autonómico. Teoría y Realidad Constitucional, 38, 277-304. Disponible en: https://doi. org/10.5944/trc.38.2016.18590.

— (2018). El poder de coerción del art. 155 CE como función del Estado total. Algunas consideraciones sobre su aplicación al desafío secesionista de Cataluña. En R. Punset y L. Álvarez (coords.). Cuatro décadas de una Constitución normativa (1978-2018). Estudios sobre el desarrollo de la Constitución española (pp. 583-609). Cizur Menor: Civitas.

Álvarez García, A. (2019). Poderes de necesidad y fuerzas armadas (I): las respuestas jurídicas previstas por la legalidad ordinaria ante situaciones de crisis. Revista General de Derecho Administrativo, 50, 2.

Bernardi i Gil, X. (2019), L'aplicació de l'article 155 de la Constitució espanyola al Govern i l'Administració de la Generalitat de Catalunya. Revista catalana de dret públic, 2 (número especial), 21-44.

Calafell Ferrá, V. J. (2000). La compulsión o coerción federal (Estudio del artículo 155 de la Constitución española). Revista de Derecho Político, 48-49, 99-146. Disponible en: https://doi.org/10.5944/rdp.48-49.2000.8790.

Comissionat per al Desplegament de l'Autogovern (2018). Els efectes de la intervenció de la'Administració General de l'Estat mitjançant l'aplicació de l'article 155CE a la Generalitat de Catalunya. [Barcelona]: Generalitat de Catalunya, Comissionat per al Desplegament de l'Autogovern. Disponible en: https://bit.ly/33vkqZf.

Cruz Villalón, P. (1981). La protección extraordinaria del Estado. En A. Predieri y E. García de Enterría (dirs.). La Constitución española de 1978. Estudio sistemático (pp. 689-717). Madrid: Civitas.

— (1984). Coerción estatal. En J. J. González Encinar (ed.). Diccionario del sistema politico español (pp. 56-62). Madrid: Akal.

- (1999). La curiosidad del jurista persa y otros estudios sobre la Constitución. Madrid: Centro de Estudios Políticos y Constitucionales.

De la Quadra-Salcedo Fernández del Castillo, T. (2018). Reflexiones sobre el artículo 155 de la Constitución y la protección del interés general de España. Revista Española de Derecho Administrativo, 191, 25-76.

Freixes Sanjuán, T. (2019). El artículo 155 de la Constitución: marco jurídico y algunas reflexiones sobre su aplicación a Cataluña. En Asociación de Letrados del Tribunal 
Constitucional. El artículo 155 de la Constitución (pp. 13-51). Madrid: Tribunal Constitucional; Centro de Estudios Políticos y Constitucionales.

García Roca, J. (2019a). Diez tesis sobre la intervención extraordinaria del Estado en las comunidades autónomas (artículo $155 \mathrm{CE}$ ) tras su aplicación en Cataluńa. En Asociación de Letrados del Tribunal Constitucional. El artículo 155 de la Constitución (pp. 173-239). Madrid: Tribunal Constitucional; Centro de Estudios Políticos y Constitucionales.

- (2019b). «Il tempo moderato» de la intervención coactiva del Estado (artículo 155 CE) en Cataluña: un comentario a las SSTC 89 y 90/2019 en particular, proporcionalidad y test de necesidad o razonabilidad de los medios. Teoria y Realidad Constitucional, 44 , 503-524. Disponible en: https://doi.org/10.5944/trc.44.2019.26026.

García Torres, J. (1984). El artículo 155 de la Constitución y el principio constitucional de autonomía. En Organización territorial del Estado (Comunidades autónomas) (pp. 11891303). Madrid: Instituto de Estudios Fiscales.

(2019a). El artículo 155 paso a paso. En Asociación de Letrados del Tribunal Constitucional. El artículo 155 de la Constitución (pp. 105-173). Madrid: Tribunal Constitucional; Centro de Estudios Políticos y Constitucionales.

- (2019b). Las medidas necesarias. En VV. AA. La Constitución de los españoles. Estudios en homenaje a Juan José Solozábal (pp. 501-518). Madrid: CEPC.

Gil-Robles Delgado, J .M. (1988). Comentario al artículo 155. En O. Alzaga (dir.). Comentarios a las leyes politicas. Constitución española de 1978 (pp. 501-518). Madrid: Edersa.

Gómez Orfanel, G. (1986). Excepción y normalidad en el pensamiento de Carl Schmitt. Madrid: Centro de Estudios Constitucionales.

- (2005). La coerción federal en el derecho comparado. Cuadernos de Derecho Público, 26, 41-60.

- (2018). Artículo 155. En M. Rodríguez-Piñero y M. E. Casas (dirs.). Comentarios a la Constitución española, vol. II (pp. 1636-1650). Madrid: Fundación Wolters-Kluwer.

González Hernández, E. (2013). El «interés general» y «el interés general de España». Entre la unidad y la autonomía. En VV. AA. Constitución y desarrollo político. Estudios en Homenaje al profesor J. de Esteban (pp. 1523-1553). Valencia: Tirant lo Blanch.

- (2016). El artículo 155 CE y la LO 15/2015, de 17 de octubre, de reforma de la LOTC: ¿ineludible reciprocidad o círculo perverso? Teoría y Realidad Constitucional, 37, 529-557. Disponible en: https://doi.org/10.5944/trc.37.2016.17015.

Kluth, W. (1998). Prohibición de exceso y principio de proporcionalidad en derecho alemán. Cuadernos de Derecho Público, 5, 219-237.

Martín i Alonso, G. (2018). Sistematització de les mesures i decisions adoptades per les institucions i òrgans estatals a l'empara de l'article $155 \mathrm{CE}$, en diversos àmbits materials. Barcelona: Institut d'Estudis de l'Autogovern.

Meinecke, F. (1983). La idea de la Razón de Estado en la Edad Moderna. Madrid: Centro de Estudios Constitucionales.

Moderne, F. y Bon, P. (1981). Les Autonomies regionales dans la Constitution espagnole. Paris: Económica.

Muñoz Machado, S. (1982). Derecho público de las comunidades autónomas. Madrid: Civitas. 
Nieto Jiménez, J. C. (2020). Gobierno, Senado y Tribunal Constitucional ante la coerción estatal. El procedimiento del artículo 155 de la Constitución española. Madrid: Centro de Estudios Políticos y Constitucionales.

Ridao Martín, J. (2018). La aplicación del artículo 155 de la Constitución a Cataluña. Un examen de su dudosa constitucionalidad. Revista Vasca de Administración Pública, 111, 169-203.

Rohan, E. (1988). Del interés de los Principes y Estados de la Cristiandad. Madrid: Tecnos.

Satrústegui Gil-Delgado, M. (2017). Un instrumento para la defensa del Estado: el artículo 155 de la Constitución. En VV. AA. Retos del Estado y la Administración en el siglo XX: Libro homenaje a Tomás de la Quadra Salcedo (pp. 1859-1893) Valencia: Tirant lo Blanch.

Schmitt, C. (1924). Die Diktatur des Reichspräsidenten nach Art. 48 der Reichsverfassung. En Actas de la Asociación de Profesores de Derecho Constitucional, Berlin, 14 y 15 de abril de 1924 (pp. 65-105). Berlín: VVDStRL.

Tolivar Alas, L. (1981). El control del Estado sobre las comunidades autónomas. Madrid: IEAL. Vandelli, L. (1982). El ordenamiento español de las comunidades autónomas. Madrid: IEAL.

Vintró Castells, J. (2019). El artículo 155 de la Constitución: marco jurídico y algunas reflexiones sobre su aplicación a Cataluña. En Asociación de Letrados del Tribunal Constitucional. El artículo 155 de la Constitución (pp. 53-104). Madrid: Tribunal Constitucional; Centro de Estudios Políticos y Constitucionales.

Vírgala Foruria, E. (2005). La coacción estatal del artículo 155 de la Constitución. Revista Española de Derecho Constitucional, 73, 55-110. 